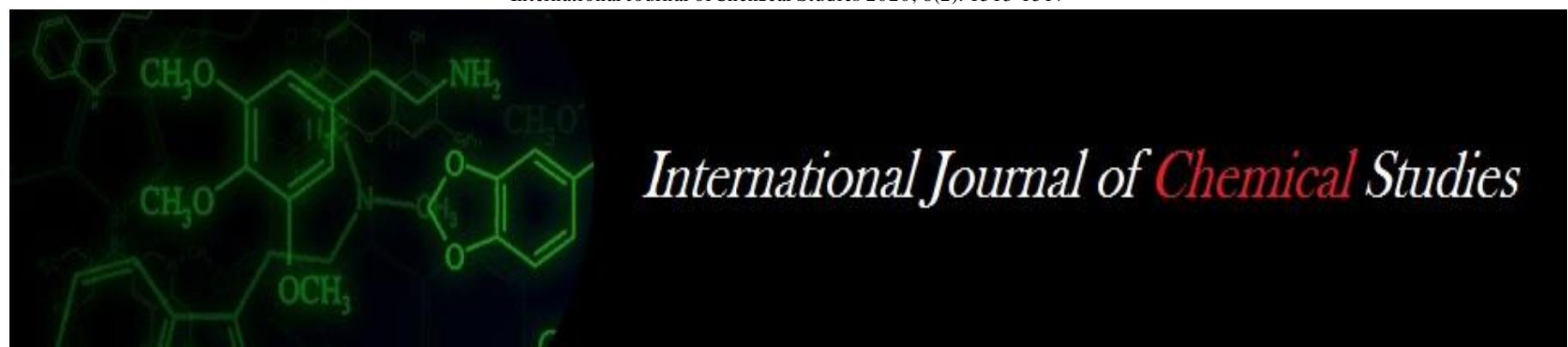

P-ISSN: 2349-8528

E-ISSN: 2321-4902 Www.chemijournal.com IJCS 2020; 8(2): 1513-1517 (C) 2020 IJCS

Received: 16-01-2020 Accepted: 18-02-2020

Mutteppa Chigadolli

Ph. D Scholar, Department of Agricultural Extension, UAS, GKVK, Bengaluru, Karnataka, India

Dr. B. Krishnamurthy Professor, Department of Agricultural Extension, UAS, GKVK, Bengaluru, Karnataka, India

Dr. YN Shivalingaiah Professor, Department of Agricultural Extension, UAS, GKVK, Bengaluru, Karnataka, India

Corresponding Author: Mutteppa Chigadolli Ph. D Scholar, Department of Agricultural Extension, UAS, GKVK, Bengaluru, Karnataka, India

\section{Relationship and extent of contribution of profile characteristics of turmeric growers towards their knowledge about improved cultivation practices in Belagavi, Karnataka}

\author{
Mutteppa Chigadolli, Dr. B. Krishnamurthy and Dr. YN Shivalingaiah
}

DOI: https://doi.org/10.22271/chemi.2020.v8.i2w.8975

\begin{abstract}
The study was conducted in Belagavi district of Karnataka. A total of 120 respondents were selected randomly which includes 60 respondents from Gokak and Raibag taluks where production, productivity and area under turmeric was found maximum. The data collected from the respondents using structured interview schedule and was analyzed and tabulated using statistical tools like correlation and multiple regression analysis. The findings of the study revealed that, the variables landholding, annual income, risk orientation, farming experience, economic motivation and scientific orientation have significant relationship with the knowledge of turmeric growers at 5 percent level. The independent variables education, extension contact, extension participation, market orientation, achievement motivation and innovativeness have significant relationship with knowledge level of turmeric growers at 1 percent level. Whereas the other profile characteristic variables viz. age, deferred gratification, and social participation were found non-significant. It also revealed that extent of contribution of profile characteristics towards the knowledge about improved cultivation practices by turmeric growers indicated that all the selected independent variables put together contributed about 79.99 (with $R$ value 0.7999 ) percent variation in the turmeric growers' knowledge about improved turmeric cultivation practices which was explained by fifteen independent variables. It was also noticed that out of fifteen independent variables only one variable is positive and significant at 5 percent level, six variables are found positive and significant at 1 percent level and eight variables are positive but non-significant contribution at either 5 or 1 percent.
\end{abstract}

Keywords: Turmeric growers, relationship, extent of contribution, knowledge, improved cultivation practices

\section{Introduction}

India is known as 'Land of Spices'. India is the largest producer, consumer and exporter of spices in the world followed by China. India utilizes 90 percent of its production for domestic consumption. About 109 spices are notified all over world where India as single country grows 63 species among them. Share of spices in total agricultural export of India is about six percent. India's share of world spice trade is about 45 to 50 percent by volume and 25 to 30 percent by value.

In India turmeric is growing in as many as 25 states and among them Telangana, Andhra Pradesh, Karnataka, Tamil Nadu and Gujarat are the leading producers of turmeric. India had nearly 1.94 lakh hectares under cultivation of turmeric with a total production of 10.52 lakh tons during the year 2016-17. Telangana topped both in area and production with 50,000 hectares and 2,55,000 tons production during the year 2016-17 followed by Tamil Nadu in area with 29,306 hectares and Andhra Pradesh in production with 134,122 tons. (Anonymous 2017) [2].

In Karnataka, turmeric was cultivated in an area of 14,994 hectares with a production of 76,490 tons during the year 2016-17. Belagavi district is second largest turmeric producing district with an area of 3,498 hectares and production of 33,861 tons of turmeric only after Chamarajanagar district with an area of 8,230 hectares and production of 36,031 metric tons turmeric. Mysuru (3,130 ha \& 22,065 metric tons) Bagalkot (2,585 ha \& 12,912 metric tons) districts stood in third and fourth rank both in area and production of turmeric in the state during the year 2015-16. (Anonymous 2016) ${ }^{[1]}$.

$$
\sim 1513 \sim
$$


Innovations were adopted early and more rapidly by those farmers who possess the attributes, listed by Rogers and Shoemaker (1971). Remaining farmers would follow them slowly based on their resource matrix and various other parameters resulting in considerable time gap. Studying the relationship and extent of contribution of profile characteristics of turmeric growers would certainly help to plan, develop and execute the suitable extension strategies to reach the slow adopters. Thus, reducing the time gap and increasing the rate of adoption of improved practices. Thus, the study has been carried out with the specific objective to study the relationship and extent of contribution of profile of turmeric growers towards the adoption of improved cultivation practices in turmeric.

\section{Methodol ogy}

The existing study was conducted using the "Ex-post facto" research design which was found suitable and appropriate for this study as the phenomenon/event has already been occurred or happened. This research study was carried out in the Belagavi district of Karnataka as it stands in the second position in both area under turmeric and production of turmeric and first in productivity of turmeric. Among ten taluks in Belagavi district Raibag and Gokak are the two leading taluks in both area and production of turmeric. Hence these two taluks are purposively selected for the study. From each taluk three villages were selected based on maximum area under turmeric cultivation which were identified by consulting with the Raitha Sampark Kendras (RSKs). From each village, 20 turmeric growing farmers were selected randomly for the study. Data collection was made through personal interview method using pre-tested interview schedule. Thus, the final sample comprises of 120 respondents spread over in three different villages from each taluk. Mean, standard deviation, correlation and multiple regression analysis were used for tabulation and analysis of data.

\section{Results and Discussion \\ Overall adoption level of turmeric growers with respect to improved cultivation practices}

The Table 4.5 indicates the distribution of turmeric cultivators with respect to their overall adoption of improved turmeric cultivation practices shows that 47.50 percent of turmeric farmers were in medium level adoption, 32.50 percent of turmeric farmers had high extent of adoption and it is also noticed that only 20.00 percent had low level adoption of improved turmeric cultivation practices.

Nearly half of the turmeric farmers had medium extent of adoption of improved cultivation practices because of nonavailability of inputs timely whenever required like quality seed material, bio-fertilizers, non-availability of farm yard manure etc. With respect to the integrated nutrient management, pest and disease management and weed management more than half of turmeric growers were in partial adoption category i.e., they were applying more than recommended quantities except farmyard manure and biofertilizers. When they were asked why they use more than recommended quantity, the reply is that if recommended quantities were applied then the expected yield will not come. Some of turmeric growers did not use the recommended inputs provided by the private agencies due to high cost of inputs. The findings of this study are in compliance with research findings of Ganeshprasad (2006) [5] and Shalini (2017) [14]
Table 1: Overall Extent of Adoption of improved cultivation practices by turmeric growers $(\mathrm{N}=120)$

\begin{tabular}{|c|c|c|c|}
\hline \multirow{2}{*}{ Sl. No. } & \multirow{2}{*}{ Extent of adoption } & \multicolumn{2}{|c|}{ Turmeric growers } \\
\hline & & Number & Percent \\
\hline 1 & Low & 24 & 20.00 \\
\hline 2 & Medium & 57 & 47.50 \\
\hline 3 & High & 39 & 32.50 \\
\hline & Total & 120 & 100.00 \\
\hline
\end{tabular}

Mean $=52.51 ;$ Standard deviation $=6.46$

\section{The relationship between knowledge of turmeric growers with the independent variables}

Table 1 reveals that the variables landholding, annual income, risk orientation, farming experience, economic motivation and scientific orientation have significant relationship with the knowledge of turmeric growers at 5 percent level. The independent variables education, extension contact, extension participation, market orientation, achievement motivation and innovativeness have significant relationship with knowledge level of turmeric growers at 1 percent level. Whereas the other profile characteristic variables viz. age, deferred gratification, and social participation were found nonsignificant.

\section{Age with Knowledge}

There was a non-significant relationship between age and knowledge of turmeric growers regarding improved cultivation practices as indicated in Table 1. This generalize that farmers of different age group have similar capacity to gain knowledge level regarding improved cultivation practices in turmeric. The knowledge level of younger and middle-aged farmers was higher than old aged farmers. The reason may be that, the old-aged farmer's interest in understanding and learning ability will be decreased hence the result showed the non-significant relation and the above findings were in conformity with findings of Chavan (2015) ${ }^{[3]}$ and Naveen (2016) ${ }^{[12] .}$

\section{Education with knowedge}

Table 1 , showed positive (0.256) and significant relationship at 1 percent level of significance for education with the knowledge level of farmers about improved cultivation practices in turmeric. Education helps in improving the knowledge level of turmeric growers. Higher the education then better will be the discussions and interactions with resource rich persons which helps to interpret in better way and understand the worth of practices. It is well-known fact that an educated individual will be in a better position to gather more information, better understanding capability and interpret even the complicated information related to improved and new practices. Obviously, the acquisition and retention of recent practices knowledge is more among the educated farmers and they became more receptive towards the innovative things, compared to the illiterate farmers. The findings were in conformity with research findings of Sakeer (2010) ${ }^{[13]}$ and Chethan (2011) ${ }^{[4]}$.

\section{Landhol ding with Knowledge}

There was a significant relationship between the knowledge and landholding of turmeric farmers at 5 percent level of significance. The probable reason for this kind of result may be that farmers with big holdings will have more opportunities and potentialities to try and adopt the recent and improved practices in turmeric cultivation with the aim to get higher yield and to improve economic condition. As a result, 
it is quite possible that farmers with bigger land holdings have keen interest to know about new farm practices and be more receptive to such ideas, skills and other management factors, which intern on their adoption of post-harvest technologies in turmeric. This is substantiated by findings of Chavai et. al. (2015) ${ }^{[3]}$.

\section{Annual income with knowledge}

Further, Table 1, shown positively significant relation of knowledge level with annual income of turmeric growers and their knowledge level about improved practices in turmeric cultivation with the value of 0.3120 at 5 percent level of significance. Mainly may be due to the reason that the high family annual income provides enormous opportunities for repeated exposure of turmeric growers to new technology and motivates them to gain more and more knowledge about latest technologies. Hence, those farmers who had higher family income had exhibited higher knowledge level. The results of the present study are in conformation with the findings of Chethan (2011) ${ }^{[4]}$ and Chavai et. al. (2015) ${ }^{[3]}$ where annual income was positively related to knowledge level of respondents.

\section{Extension contact with knowledge}

Table 1 revealed that extension contact had significant relation with knowledge level of turmeric farmers about improved cultivation practices. The likely reason might be that, turmeric growers consulted horticulture officers, assistant horticulture officers and scientists from the Kittur Rani Chennamma College of Horticulture (KRCCOH), Arabhavi for the improved and recent information regarding the improved turmeric cultivation practices. The findings were in line with the findings reported by Chetan (2011) [4] where extension contact affected the knowledge level of respondents.

\section{Extension participation with knowledge}

It is obvious that turmeric farmers with higher level of extension participation are more favorably pre-disposed to acquire more information, to know about the improved cultivation practices in turmeric by exposure of farmers through field days, discussions with progressive farmers, Krishi mela, field trips etc. During the course of interaction and discussion with extension personnel, the turmeric growing farmers exposed themselves to many latest and improved turmeric cultivation practices. Thus, positive and significant relationship between extension participation and knowledge of turmeric growers had observed in this study at 1 percent level of significance. The findings are in relation with findings of Chetan (2011) ${ }^{[4]}$ who observed the significant relation with knowledge of vermi-compost making farmers.

\section{Risk orientation with knowledge}

The positive and significant relationship between risk orientation and knowledge level of turmeric growers about improved cultivation practices is observed at 1 percent level of significance. Turmeric is high value crop which requires to know about the improved innovations which can be practiced and adopted in order to tackle the various problems facing in traditional practices. The findings are substantiated by the findings of Shivani (2015) [15] and Naveen (2016) ${ }^{[12]}$ who found the significant relationship of risk orientation with knowledge level of farmers.

\section{Achievement motivation with knowledge}

Achievement motivation was found to had found positively significant relationship with knowledge level of farmers at 1 percent level of significance because turmeric is high value crop which motivated farmers to grow turmeric instead of sugarcane in order fulfill their needs inspite of involvement of compound practices and high risk of pest and diseases in turmeric which clearly shows the farmers motivation to get more and more yield. This is in compliance with the findings of Kumari et. al. (2017) ${ }^{[9]}$.

\section{Market orientation with knowledge}

Market orientation is found positively significant at 1 percent level of significance with knowledge level of turmeric farmers about improved turmeric cultivation practices. This is because farmers recognized the importance of grading, processing, colouring and transporting the produce to far Sangli market to get higher prices to their produce which clearly shows that market orientation has significant relation in knowing the improved practices in turmeric crop. The finding is in accordance with results of Shivani (2015) ${ }^{[15]}$ and Naveen (2016) ${ }^{[12]}$ who found significant relation of market orientation with farmers knowledge level.

\section{Farming experience with knowedge}

Farming experience of turmeric growers had positively significant relation with the knowledge of turmeric farmers because the more experienced people compare the results of their traditional practices with the modern and innovative practices which are cost effective, time saving and reduces dependency on labours. In return it motivated the experienced farmer's eagerness to know more and more improved practices than young farmers. The results are in correspondence with the finding of Gungadi (2011) [7] and Naveen (2016) ${ }^{[12]}$ who revealed significant relation with knowledge level.

\section{Social participation with knowedge}

Social participation of turmeric farmers is non-significant with knowledge level of turmeric growers because they had very poor participation in social organisations like panchayats, cooperatives, self-help groups, farmers organisations, youth forums etc., which might be reason for the non-significant relationship with knowledge level of turmeric growers. This result is in contrast to the results of Shivani (2015) ${ }^{[15]}$ and Naveen (2016) ${ }^{[12]}$.

Table 2: Relationship between independent variables and knowledge of turmeric growers $(\mathrm{N}=120)$

\begin{tabular}{|c|c|c|}
\hline Sl. No. & Characteristics & Correlation Coefficient (r) \\
\hline 1 & Age & $0.0410^{\text {NS }}$ \\
\hline 2 & Education & $0.3111^{* *}$ \\
\hline 3 & Land holding & $0.2210^{*}$ \\
\hline 4 & Annual income & $0.1990^{*}$ \\
\hline 5 & Extension contact & $0.743^{* *}$ \\
\hline 6 & Extension participation & $0.5500^{* *}$ \\
\hline 7 & Risk orientation & $0.3136^{* *}$ \\
\hline 8 & Achievement motivation & $0.2999^{* *}$ \\
\hline 9 & Market orientation & $0.3350^{* *}$ \\
\hline 10 & Farming experience & $0.2002^{*}$ \\
\hline 11 & Social participation & $0.0967^{\mathrm{NS}}$ \\
\hline 12 & Economic motivation & $0.2261^{*}$ \\
\hline 13 & Innovativeness & $0.3390^{* *}$ \\
\hline 14 & Deferred gratification & $0.1520^{\mathrm{NS}}$ \\
\hline 15 & Scientific orientation & $0.2462^{*}$ \\
\hline
\end{tabular}

*= Significant @5\% level **=Significant @ 1\% level NS=Nonsignificant 


\section{Economic motivation with knowledge}

Table 1 revealed the positive and significant relationship between economic motivation and knowledge of turmeric growers about improved turmeric cultivation practices at 5 percent level of significance. The reason might be that motivation to achieve more and reap higher profit will naturally force the turmeric growers to know more about profitable practices to maximize profit. The results are in agreement with the findings of Melkeri \& Syed (2018) ${ }^{[11]}$ and Gopi et.al. (2017) ${ }^{[6]}$ who observed that economic motivation changed the knowledge level of respondents.

\section{Innovativeness with knowledge}

Table 1 showed positive and significant relationship with the knowledge level of farmers about improved practices in turmeric cultivation at 1 percent significance level. The reason might be the farmers are interested in trying new ideas to get better yield, also to reduce the cost of cultivation and time saving. The result is in accordance with findings of Shivani (2015) [15] found significant relationship with knowledge level of respondents.

\section{Deferred gratification with knowledge}

Deferred gratification was found non-significant relationship with knowledge level of turmeric growers regarding improved cultivation practices. This might be due to the reason that farmers are not willing to postpone in adopting recent and improved practices hence this kind of results is obtained. This is in contrast to the findings of Khalanche \& Gaikwad (2008) ${ }^{[8]}$ where she found positively significant relation with tomato growers' knowledge.

\section{Extent of contribution of independent variables to the knowledge of farmers about improved cultivation practices in turmeric}

Table 3 indicates the extent of contribution of profile characteristics towards the knowledge about improved cultivation practices by turmeric growers computed through multiple regression analysis. The table 3 indicates that, $\mathrm{R}$ value 0.7999 indicated that all the selected independent variables put together contributed about 79.99 percent variation in the turmeric growers' knowledge about improved cultivation practices which were explained by fifteen independent variables. After analyzing the 15 variables, it was found that six variables namely education, extension contact, extension participation, market orientation, economic orientation and innovativeness were found positively significant at 1 percent level, whereas only one variable achievement motivation was found significant at 5 percent level and remaining seven variables age, education, landholding, risk orientation, social participation, scientific orientation and deferred gratification were found nonsignificant but positive which means they were contributing in gaining the knowledge about improved cultivation practices but not at the 1 or 5 percent significance level.

Table 3: Extent of contribution of independent variables to the knowledge of farmers about improved cultivation practices in turmeric $(\mathrm{n}=120)$

\begin{tabular}{|c|c|c|c|c|}
\hline SI No. & Characteristics & Regression Coefficient & SE of regression coefficient & 't' Value \\
\hline 1 & Age & 0.0914 & 0.0652 & $1.40^{\text {NS }}$ \\
\hline 2 & Education & 0.5716 & 0.2121 & $2.69^{* *}$ \\
\hline 3 & Land holding & -0.0282 & 0.1261 & $0.12^{\text {NS }}$ \\
\hline 4 & Annual income & 0.4350 & 0.4169 & $1.04^{\text {NS }}$ \\
\hline 5 & Extension contact & 1.6183 & 0.1309 & $12.37^{* *}$ \\
\hline 6 & Extension participation & 0.0928 & 0.0261 & $3.50^{* *}$ \\
\hline 7 & Risk orientation & 0.2554 & 0.2624 & $0.97^{\text {NS }}$ \\
\hline 8 & Achievement motivation & -0.5785 & 0.2441 & $2.37^{*}$ \\
\hline 9 & Market orientation & 0.7912 & 0.1490 & $5.31^{* *}$ \\
\hline 10 & Farming experience & -0.0212 & 0.0637 & $0.33^{\text {NS }}$ \\
\hline 11 & Social participation & 0.0574 & 0.0406 & $1.41^{\text {NS }}$ \\
\hline 12 & Economic motivation & 0.1554 & 0.5960 & $2.60^{* *}$ \\
\hline 13 & Innovativeness & 0.0779 & 0.0383 & $2.03^{* *}$ \\
\hline 14 & Deferred gratification & 0.0584 & 0.2088 & $0.28^{\text {NS }}$ \\
\hline 15 & Scientific orientation & 0.0271 & 0.1504 & $0.28^{\text {NS }}$ \\
\hline
\end{tabular}

* Significant@ @\% level

**Significant@ @ 1\% level

NS-Non-significant

SE-standard error $\mathrm{R}^{2}=0.7999$

\section{Conclusion}

Recognition of the incongruity in the independent variables of farmers and their current level of knowledge through relationship and contribution made by these independent variables is of supreme importance for selecting proper channels and means to enhance the knowledge level of farmers with respect to production technologies and enhancing productivity of turmeric through increased rate of adoption of improved cultivation practices.

\section{References}

1. Anonymous. Horticulture crop statistics of Karnataka state at a glance 2015-16. Directorate of Horticulture Lalbagh, Bengaluru, 2016.
2. Anonymous. Area, Production and productivity of major spices in India. Spice Board, India, Ministry of Agriculture and farmers welfare, Govt of India, 2017,

3. Chavai AM, Yamgar AS, Barange PK. Adoption behavior of turmeric growers about post-harvest technologies. Int. J Tropical Agric. 2015; 33(2):16471651.

4. Chethan MG. A study on knowledge and adoption of cardamom cultivation practices by the farmers of Chikkamagalur district. M. Sc. (Agri.) Thesis., Univ. Agric. Sci., Dharwad, 2011.

5. Ganeshprasad TS. An analysis of adoption, marketing and constraints of turmeric grower's in Chamarajanagar district. M. Sc. (Agri.) Thesis., Univ. Agric. Sci., Bengaluru, 2006. 
6. Gopi R, Narmatha N, Sakthivel KM, Uma V, Jothilakshmi M. Socio-economic characteristics and its relationship with information seeking pattern of dairy farmers in Tamil Nadu, Asian J Dairy \& Food Res., 2017; 36(1):16-20.

7. Gungadi ST. A study on knowledge and adoption of recommended production practices of paddy by the farmers of Tungabhadra project area, Karnataka M. Sc. (Agri.) Thesis., Univ. Agric. Sci., Raichur, 2011,

8. Khalanche VK, Gaikwad. A study of relationship between selected characteristics of the respondent paddy growers and technological gap in the paddy cultivation of Sitamarhi district of Bihar, Agriculture Update. 2008; 3(4):339-341.

9. Kumari B, Prasad SV, Sailaja V, Aparna B, Naidu MG. Relationship Between Profile Characteristics of the Farmers with Extent of Adoption of Indigenous Agricultural Practices in Rayalaseema Region of Andhra Pradesh, Bull. Env. Pharmacol. Life Sci., 2017; 6(1).

10. Lakshminarayana MT, Krishna KS, Manjunath BN, Chandrasekar S, Vaster, Anand TN. Correlates of Adoption of Sustainable Sugarcane Farming practices. Mjas. 2001; 35:168-171.

11. Melkeri AK, Syed M. Relationship between Profile Characteristics with Knowledge and Adoption of Transplanting Method of Pigeon Pea Cultivation Practices, Economic Affairs. 2018; 63(2):299-305.

12. Naveen. A Study on Knowledge and Adoption of Post harvest Technologies by Turmeric Growers of Bagalkot district. M. Sc. (Agri.) Thesis., Univ. Agric. Sci., Dharwad, 2016,

13. Sakeer Husain A. Knowledge, Adoption and Perceived Effectiveness of Indigenous Horticultural Practices in Kerala. Ph. D.Thesis., GRI (DU), Gandhigram, 2010,

14. Shalini DM. A Study on Adoption and Economic Performance of Hybrid Paddy Cultivation Practices among Farmers of Mandya district. MSc. Thesis., Univ. Agric. Sci., Bengaluru, 2017.

15. Shivani, Dechchamma. Relative Effectiveness of Different Information and Communication Technology (ICT) Gadgets on Knowledge and Symbolic Adoption of Tomato Crop Production Practices among Farmers of Karntaka-An Experimental Study, M. Sc (Agri) Thesis (Unpub.)., Univ. Agri. Sci., Bangalore. www.indiastat.com, 2015. 